\title{
Spatial Mapping of Sediment \\ Geochemistry in East Anglian Salt Marshes
}

\author{
ALEC MARTIN HUTCHINGS ${ }^{1,2}$, HAROLD J \\ BRADBURY $^{1}$, VEER GALA ${ }^{3}$, ANGUS FOTHERBY ${ }^{1}$, GILAD \\ ANTLER $^{4,5}$ AND ALEXANDRA (SASHA) TURCHYN ${ }^{1}$ \\ ${ }^{1}$ University of Cambridge \\ ${ }^{2}$ University of Calgary \\ ${ }^{3}$ Durham University \\ ${ }^{4}$ The Interuniversity Institute for Marine Sciences in Eilat \\ ${ }^{5}$ Ben-Gurion University of the Negev \\ Presenting Author: alechutchings24@gmail.com
}

The sediment beneath saline ponds in East Anglian (UK) salt marshes contains an intriguing redox phenomenon: while the sediment is largely devoid of oxygen, the porewater in pond sediment either contains dissolved iron (indicative of bacterial iron reduction) or dissolved sulfide (indicative of microbial sulfate reduction). Multiple explanations for this geochemical dichotomy have been posited in recent work: these include differences in bioturbation, the flux of organic carbon to the sediment, and iron delivery across the salt marsh platform.

Here, we use machine learning to better understand how the position of a pond relative to tidal creeks on a salt marsh might influence pond sediment chemistry. A model was fit to a training dataset of $>600$ ponds consisting solely of geometric features (e.g., distances of a pond to a creek and the area and perimeter of a pond). We use this trained model to reconstruct spatial geochemistry in three sites and compare them to field observations to evaluate the efficacy of the model; these sites range from $100 \mathrm{~m}$ to $100 \mathrm{~km}$ away from the training dataset. We find high ( $>80 \%)$ accuracies of prediction for all sites, suggesting that tidal creeks impart an important role in determining sediment geochemistry, and that this process is ubiquitous across the region. We propose the following two reasons that tidal creeks exert this level of control: (1) the flux of overlying water - and the chemical species that it contains-will differ based on the pond's proximity to a creek and, (2) that the age of a pondand thus how geochemically evolved it has become-will reflect its proximity to a tidal creek. We finally discuss how pervasive this process might be in other salt marsh systems.

Understanding spatial differences of redox conditions in salt marsh sediment will become important for understanding how these locations sequester or release carbon-particularly in the context of future land use change - and for better understanding the environmental mechanisms behind redox variability on regional scales. 